Uluslararası Mühendislik

International Journal of

Engineering Research and

Development

10.29137/umagd.817981

Cilt/Volume:12 Sayı/Issue:3 Aralık/December 2020 Özel Sayı/Special Issue

Araştırma Makalesi / Research Article

\title{
Performance Analysis for Load Frequency Control of Interconnected Power Systems with Different Techniques
}

\author{
Feyza Nur Çakıcı $^{1}$ iD ${ }^{\text {İbrahim Eke }}{ }^{1}$ iD, Mustafa Saka ${ }^{2}$ iD , M. Cengiz Taplamacıoğlu ${ }^{2}$ iD \\ ${ }^{1}$ Kirikkale University, Department of Electrical and Electronics Engineering, Kirikkale, TURKEY \\ ${ }^{2}$ Gazi University, Department of Electrical and Electronics Engineering, Ankara, TURKEY
}

Başvuru/Received: 01/11/2020

Kabul / Accepted: 14/12/2020

Çevrimiçi Basım / Published Online: 31/12/2020

Son Versiyon/Final Version: $31 / 12 / 2020$

\begin{abstract}
In the interconnected power system, frequency is one of the most important criteria determining system stability. Since interconnected systems consist of more than one region, load frequency control (LFC) is very complicated. For this reason, load frequency control analysis has been performed for interconnected power systems consisting of two and four regions in this article. Vortex Search Algorithm (VSA), Salp Swarm Algorithm (SSA) and Sine Cosine Algorithm (SCA) are used to determine the filter coefficient proportional-integral-derivative controller (PID-N) parameters of these interconnected systems. The results obtained are analyzed for overshoot (OS), undershoot (US) and settling time (ST) values for each region. It is observed that different system performances are obtained using by these methods. In addition, all system performances are significantly improved with the selected methods.
\end{abstract}

Keywords

"LFC, PID-N controller, SCA, SSA, VSA" 


\section{Introduction}

Depending upon the best industrial revolution as it increases, the energy consumption is also increased rapidly. In addition, the level of development of countries and the amount of electrical energy consumed per person draws an increasing graphic. While energy consumption is increasing, the quality of energy is also because an important issue. Mainly system frequency and voltage determine the power quality. It takes longer time to control the frequency than the voltage. Thus, frequency control in the power system should be controlled first. In this power system, the frequency can remain constant with the active power balance, as the rated frequency depends on the active power balance produced and consumed.

If the change in the frequency of the power system exceeds the acceptable level, it can cause significant instability problems. It may stop the power plants in the system and even crash the system. For example, the system crash that occurred in Turkey in 2015 and affected 77 million people. This clearly shows how important load frequency control is for electric power systems. Fixed frequency values 49.2-50.8 Hz for Union for the Coordination of Transmission of Electricity (UCTE) and $50 \mathrm{~Hz}$ for Turkey as it is determined (UCTE, 2004). Changes in the active power balance lead to changes in frequency. Because the frequency is effective at every point of system, it is noticeable in the entire system.

Deviations in frequency can occur if the active power balance in the system exceeds the demanded power. The speed of the generator increases, so it increases the system in frequency. Conversely, the frequency decreases if the amount of production is less than the demanded power. Because of this, the mismatch between generated energy and the demanded energy causes deviations in frequency. Although the frequency deviation that occurs is not the desired situation, it is not possible for this situation to not occur.

Deviations in the frequency of the system are fixed by controlling the generator. Generators feed loads so ensuring regular operation of the system. Load control of the generator is provided by load frequency control. As a result, adjusting generated electricity and frequency according to the demanded electricity and frequency is called 'Load Frequency Control' (Gümüş, 2012).

PID-based controllers are often used to reduce the continuous state error occurring at frequency. Different optimization algorithms have been used to determine the optimal values of these control parameters for LFC. Particle Swarm Optimization Algorithm (PSO) (Gözde, et al., 2010), Harmony Search Algorithm (HSA) (Omar, et al., 2015), Bacterial Foraging Optimization Algorithm (BFOA) (Ali\&Abd-Elazim, 2011), Ant Colony Algorithm (ACO) (Omar, et al., 2013), Artificial Bee Algorithm (ABC) (Rathar,et al., 2011), Central Force Algorithm (CFO) (Formato, 2007), Firefly Algorithm (FA) (Naidu, et al., 2013), League Championship Algorithm (LCA) (Kashan, et al., 2009), Group Search Optimization (GSO) (He, et al., 2009), Gravitational Search Algorithm (GSA) (Safi, et al., 2018), Teaching-Learning-Based Optimization (TLBO) (Sahu, et al., 2015), methods are some of them. In this study, PID-N controller is used to perform load frequency control of two and four region power systems. The optimal control parameters of PID-N controller are determined comparatively by VSA (Dogan,et al., 2015), SSA (Mirjalili,et al., 2017) and SCA (Mirjalili, et al, 2016). Obtained results are examined by taking into account different system performances.

The remainder of the article is as follows: In the section 2, using comprehensive model for LFC is expressed and also some definitions are given. In the section 3, information about the PID-N controller is given. In the section 4, the methods used to adjust the controller parameters (VSA, SSA and SCA) are briefly described. In the section 5, obtained results for selected interconnected systems are given and in the section 6 main outputs of the study are expressed as the Conclusions.

\section{Load Frequency Control}

Load frequency control is divided into three main parts. These are primary frequency control, secondary frequency control and tertiary frequency control.

When the demanded and generated electrical energy is not equal, the frequency deviates and following the primary control ensures the stability of the frequency by keeping the frequency deviations at an acceptable level. Frequency deviation is $\pm 200 \mathrm{mHz}$ according to UCTE criteria (Yalçın, et al., 2016). If the frequency deviation exceeds the specified value, the primary frequency control is carried out by the speed regulator located in the production center of the power systems.

Since sudden load changes may occurred in power systems, only primary frequency control cannot keep the frequency at rated value. In this case, it causes permanent state error. To eliminate the permanent state error, secondary frequency control is activated and controls the flow of power between systems. Area Control Error (ACE) information is obtained by collecting information on the frequency and connection line. Secondary frequency control returns the frequency to the rated value using Area Control Error information. As a result, primary frequency control intervenes suddenly and urgently to frequency deviation, while secondary control literally intervenes. 
In tertiary frequency control, it is achieved by having secondary reserves by increasing/decreasing in the power of generators or by providing controlled loads in frequency distortions occurring due to other reasons. In addition, the other purpose of this control is to provide the power generation of each unit with the most economical way of demanded electricity.

In an interconnected power system, the stable operation of system can be achieved by keeping the frequency deviation in specific limits. In order to keep the frequency specific band width, the energy produced and the energy consumed must be equal. However, the frequency decreases as the load increases in the system and the frequency increases as the load decreases. The process of adjusting the changing load in the system to the generated power is called speed regulation (Karyeyen, et al. 2009). In this case, it causes the generator and turbines to go beyond the nominal frequency. It can cause the system breakdown.

Multi-region power system models can be thought about combination of a lot of single-region power system models. In the case of a load change in the first region, the load in frequency $\left(\Delta f_{N}\right)$ is shown in equation (1). Where $\mathrm{R}$ stands for speed regulation, $\mathrm{D}$ for load damping constant and $\Delta P_{L}$ load disturbance.

$\Delta f_{N}=\frac{-\Delta P_{L}}{\frac{1}{R_{1}}+\cdots+\frac{1}{R_{N}}+D_{1}+\cdots D_{N}}$

The power deviation $\Delta P_{i j}$ that will occur on the connecting line of a multi-region power system is shown in the equation (2).

$\Delta P_{i j}=\frac{-\Delta P_{L i}+\left(\frac{1}{R_{j}}+D_{2}\right)}{\frac{1}{R_{1}}+\cdots+\frac{1}{R_{i}}+D_{1}+\cdots+D_{i}}$

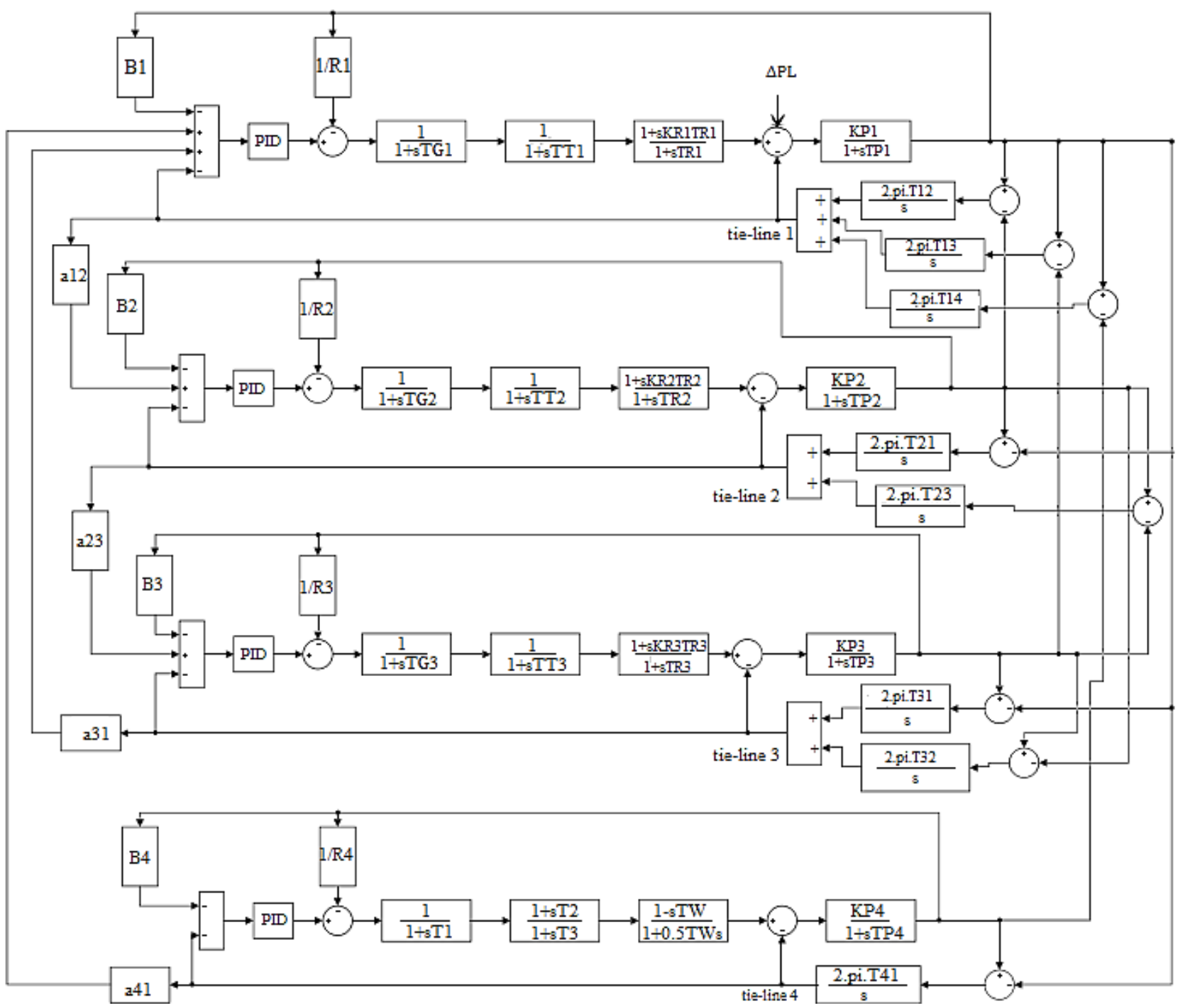

Figure 1. Multi-region power system model 
Area control error is an important parameter to realize secondary frequency control. ACE (3) are obtained by collecting power and frequency deviation. This can be expressed in the following equation:

$A C E_{i}=\sum_{j=1}^{n} \Delta P_{t i e_{i j}} \pm \beta_{i} \Delta f$

$\beta_{N}$ represents the frequency polarization coefficient.

$\beta_{i}=\frac{1}{R_{i}}+D_{i}$

Calculated ACE values are used as the input data of the recommended PID-N controller. Thus, the optimal values of the controller parameters are determined and ACE is minimized.

The transfer function of the blocks in the considered LFC model are expressed in the following equations.

Governor changes the position of the control valve to adjust the steam flow to the turbine. The transfer function is given in equation (5). Where TG stands for speed regulator time constant.

$\frac{1}{s T G+1}$

The part diving the generator in the turbines is the drive unit. The transfer function is given in equation (6). Where TT stands for turbine time constant.

$\frac{1}{s T T+1}$

Generator/Load transfer function is expressed in equation (7). Where KP stands for system gain and TP system time constant.

$\frac{K P}{S T P+1}$

Tie-Line connects the two spate areas. Transfer function is expressed in equation (8). Where $\mathrm{T}_{\mathrm{ij}}$ stands for synchronization coefficient.

$\frac{2 \times \pi \times T_{i j}}{s}$

Intermediate-Heater transfer function is expressed in equation (9). Where KR stands for Intermediate heating gain and TR for intermediate heating gain.

$\frac{K R \times T R \times s+1}{T R \times s+1}$

Hydro turbine transfer function is expressed in equation (10). Where TW stands for hydro turbine.

$\frac{1-s \times T W}{1+0.5 * s \times T W}$

Where stands for $\mathrm{T} 2$ and $\mathrm{T} 3$ synchronization coefficient.

$\frac{1+S \times T 2}{1+S \times T 3}$

\section{PID-N Control}

PID controller hasn't caused a problem in low order and linear systems. However, PID adjustment is slow in the changes that occur in nonlinear power systems. Also, frequency adjustment is difficult in multi-region power systems. PID controller may not give desired system performances in multi-region systems. For this reason, PID-N controller is proposed and its parameter values are found with VSA, SSA and SCA methods in this study. PID-N controller can be illustrated as follows: 


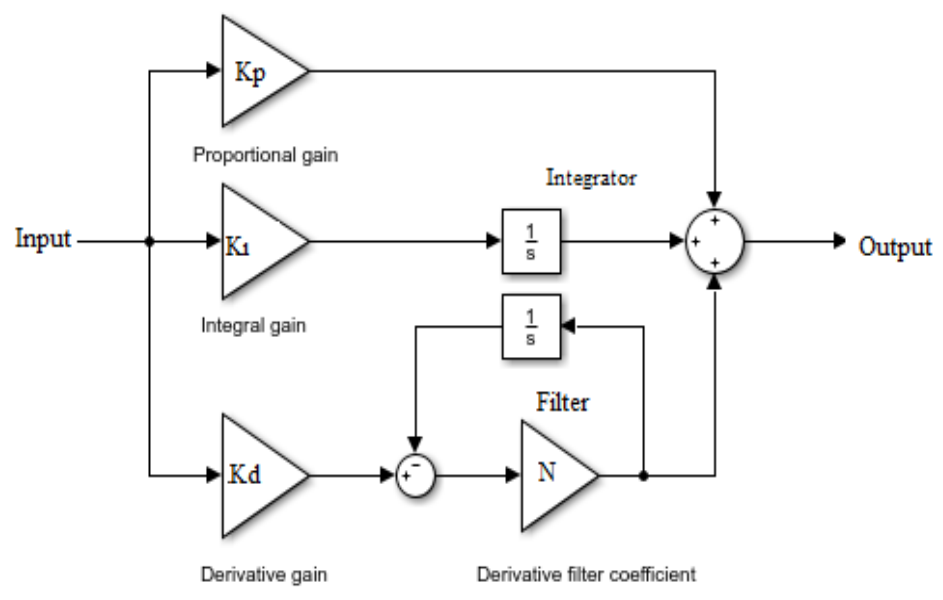

Fig. 2. PID-N controller model (Sahu, et al., 2014)

The increase or decrease of the power as a result of the changes in the load is carried out by speed regulators. The speed regulator is adjusted by the controller. Load frequency control is performed by adjusting the parameter values of the PID-N controller. The PID-N controller consist of four parameters $\mathrm{K}_{\mathrm{P}}, \mathrm{K}_{\mathrm{I}}, \mathrm{K}_{\mathrm{D}}$ and N. PID-N controller is defined as follows:

$K_{P}+\frac{K_{I}}{s}+K_{D} \times \frac{N}{\left(1+\frac{N}{s}\right)}$

Definitions of LFC system parameters are given following table:

Table 1. Abbreviations

\begin{tabular}{lc}
\hline & Symbols \\
\hline Speed regulation (Hz/MW) & $\mathrm{R}$ \\
Load damping constant (MW/Hz) & $\mathrm{D}$ \\
Turbine time constant (sn) & $\mathrm{TT}$ \\
Speed regulator time constant $(\mathrm{sn})$ & $\mathrm{TG}$ \\
Intermediate heating gain & $\mathrm{KR}$ \\
System time constant & $\mathrm{TP}$ \\
System gain & $\mathrm{KP}$ \\
Synchronization coefficient & $\mathrm{T}_{\mathrm{ij}}$ \\
Integral constant & $\mathrm{K}_{\mathrm{I}}$ \\
Hydro turbine & $\mathrm{TW}$ \\
Proportional constant & $\mathrm{K}$ \\
Derivate coefficient & $\mathrm{K}_{\mathrm{D}}$ \\
Filter coefficient of controller & $\mathrm{N}$ \\
Filter polarization coefficient & $\beta$ \\
Frequency change & $\Delta f$ \\
Tie-line load flow change & $\Delta P_{t i e}$ \\
Area control error & $\mathrm{ACE}$ \\
Load disturbance (MW) & $\Delta P_{L}$ \\
Intermediate heating time constant & $\mathrm{TR}$ \\
\hline
\end{tabular}




\section{Using Methods to Set Controller Parameters}

Vortex Search Algorithm (VSA) has good balance between exploration and exploitation. Salp Swarm Algorithm (SSA) has important features of adaptability, robustness and scalability. It is also easy to apply. Sine and Cosine Algorithm (SCA) ensures high reconnaissance and avoidance of local optima. For these reasons, VSA, SSA and SCA are selected and applied to multi region LFC systems.

\subsection{Vortex Search Algorithm}

The vortex search algorithm is a single solution based mete-heuristics method related to global optimization problems. The algorithm is called the 'Vortex Search Algorithm' because the search behavior of the Vortex Search Algorithm is inspired by the vortex model of the stirring liquids (Dogan, et al., 2015).

The vortex pattern in two dimensional space is modeled by nested circles (Dogan, et al., 2015). Center and radius are determined the first biggest circle according to the problem dimension and upper-lower limits. Solutions are generated in the circles. Every iteration, the best solution is selected as next circle center and decreased the radius of circle. This process continues until the termination criteria are met.

Using equation (13), the first center $\mu o$ can be calculated.

$\mu_{0}=\frac{\text { upper limits }+ \text { lower limits) }}{2}$

The lower limit and the upper limit in the equation (13) express the boundaries in d-dimensional space problems. VSA initial radius is found by the following equation (14) where for $\sigma_{0}$ large value should be chosen. Thus, the full coverage of the search space is provided in the first step.

$\sigma_{0}=\frac{\max (\text { upper limits })-\min (\text { lower limits })}{2}$

Before the selection phase, candidate solutions must be within the search limits. If solution exceed boundaries, equation (15) is shifted to expressed boundaries.

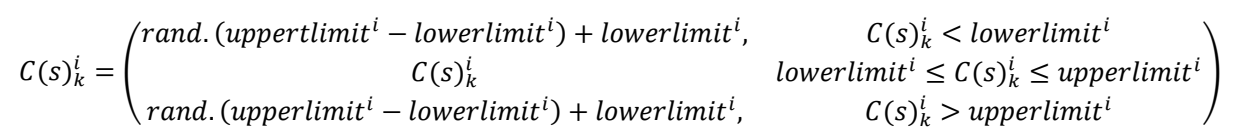

where $\mathrm{k}=1,2, \ldots \mathrm{n}$ and $\mathrm{i}=1,2, \ldots \ldots \mathrm{d}$ and radius are uniformly distributed random numbers. In the VSA algorithm, the last radius is reduced. The inverse of the gamma function is used in the halftone reduction. The disadvantage of using this method to set the radius is that the speed of convergence depends on the number of iterations. As the number of iterations (step size decreases) the search increases in the solution. In some cases, it may be advantageous to investigate the relevant search space extensively.

$r_{0}=\sigma_{0} \cdot\left(\frac{1}{\mathrm{x}}\right) \cdot \operatorname{gammaincinv}\left(\mathrm{x}, a_{0}\right)$

$r_{t}=\sigma_{0} \cdot\left(\frac{1}{\mathrm{x}}\right) \cdot \operatorname{gammaincinv}\left(\mathrm{x}, a_{t}\right)$

$a_{t}=a_{0}-\frac{t}{\text { MaxItr }}$

$a_{0}$ is chosen as $a_{0}=1$ to ensure full converage of the search space in the first iteration. $\mathrm{t}$ is the iteration index and the MaxItr is the maximum number of iterations. $r_{0}$ is the initial radius calculated from equation (16).

Pseudo code and flow diagram of VSA are given in Table 2 and in Figure 3 respectively. 
Table 2. VSA for Pseudo Code

\section{Initial}

Determines the population size

Determines the number of iterations $(\mathrm{t})$

Set upper and lower limits for $\mathrm{K}_{\mathrm{P}}, \mathrm{K}_{\mathrm{I}}, \mathrm{K}_{\mathrm{D}}, \mathrm{N}$

Initial center $\mu_{0}$ with $\mu_{0}=\frac{\text { upper limits }+ \text { lower limits })}{2}$

Initial radius $\sigma_{0}$ with $\sigma_{0}=\frac{\max (\text { upper limits) }-\min (\text { lower limits) }}{2}$

Fitness of the best solution which is found so far gmin=inf

$\mathrm{t}=1$;

Repeat

Generated solution set $\mathrm{C}(\mathrm{s})$ with Gaussian distribution in the search space of radius $\sigma_{0}$ centered $\mu_{0}$

$\mathrm{C}(\mathrm{s})$ check boundaries values

Iteration has the best solution itrBest $=\mathrm{C}(\mathrm{s})$

if itrBest $<$ gmin

gmin=itrBest;

gbest=itrBest;

end

Center is always shifted to the best solution which is found so far $\mu_{0}=\mathrm{gbest}$

Decrease the radius

$\mathrm{t}=\mathrm{t}+1$;

Until the maximum number of iterations is reached

Output best value found so far gbest

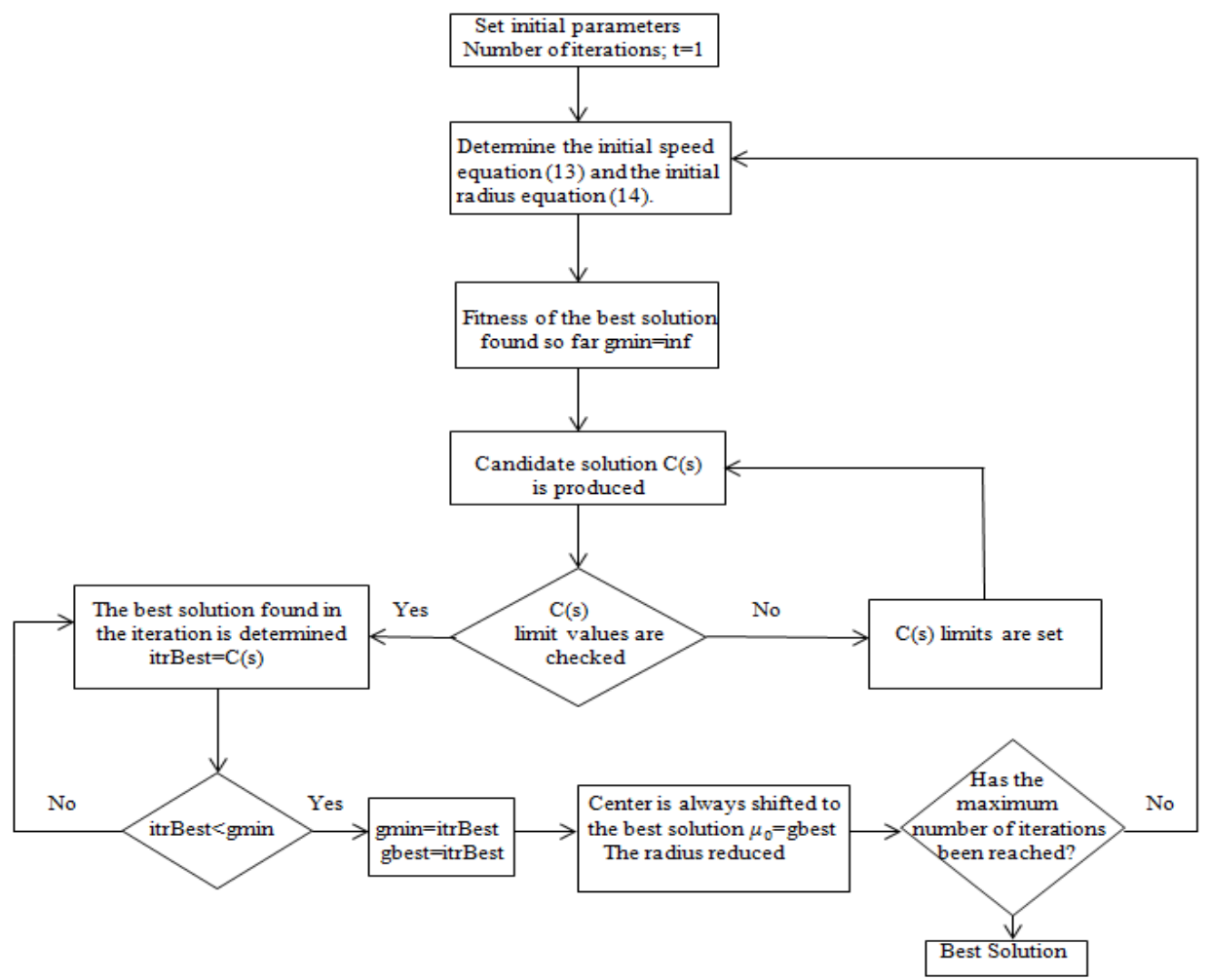

Fig. 3. VSA algorithm flow diagram

\subsection{Salp Swarm Optimization Algorithm}

SSA is one of the recently proposed algorithms. It was proposed by Mirjalili in 2017 (Mirjalili, et al., 2017). This algorithm is inspired by the fusing behavior of salps. Salp have a transparent barrel shaped body. In addition, salps belong to the Salpidae family. They are similar to the tissue of a jellyfish and act like a jellyfish. Salps form swarm in deep oceans. The formed herd is called the salp chain (Sayed, et al., 2018). This algorithm has shown by Mirjalili to be more efficient compared to other meta-heuristic methods. The SSA population is divided into two groups. These are leaders and followers. The leader is at the front of the chain. The remaining salps are known as followers. 
In the SSA algorithm, firstly the population size, number of iterations and maximum number of iterations are determined. Population upper and lower boundaries are randomly generated. The value of each individual is found using the objective function. The best solution found is assigned. The value of the parameter is updated to eliminate the imbalance between exploration and exploitation. The solutions of the leaders and followers are updated. If an undesirable situation occurs during the update in the algorithm, the range of the problem is returned. The iteration number is increased until the maximum iteration is reached, the search process is terminated. As a result of the algorithm, the best solution is produced.

Pseudo code and flow diagram of SSA are given in Table 3 and in Figure 4 respectively.

Salp position is expressed by y. F is expressed as the target food source. In the SSA algorithm, the leader position is updated with the following equations:

$y_{j}^{i}=\left\{F i+r_{1}\left(\left(\right.\right.\right.$ upperlimits $_{i}-$ lowerlimit $\left._{i}\right) r_{2}+$ lowerlimit $\left._{i}\right), \quad r_{3} \geq 0$

$y_{j}^{i}=\left\{F i-r_{1}\left(\left(\right.\right.\right.$ upperlimits $_{i}-$ lowerlimit $\left._{i}\right) r_{2}+$ lowerlimit $\left._{i}\right), \quad r_{3}<0$

$r_{1}, r_{2}$ and $r_{3}$ are random numbers. $r_{1}$, is found by the following equation (21). Also $r_{1}$, strikes the balance between explorer and exploitation.

Table 3. SSA for Pseudo Code

\section{Initial}

Set search agents

Determine upper and lower limits

Calculate the fitness value of each salp; SalpPositions=Positions

The best value of salps position; FoodPosition

Fitness of the best salps found so far FoodFitness=inf

$\mathrm{t}=1$;

while $\mathrm{t}<$ maximum iteration +1

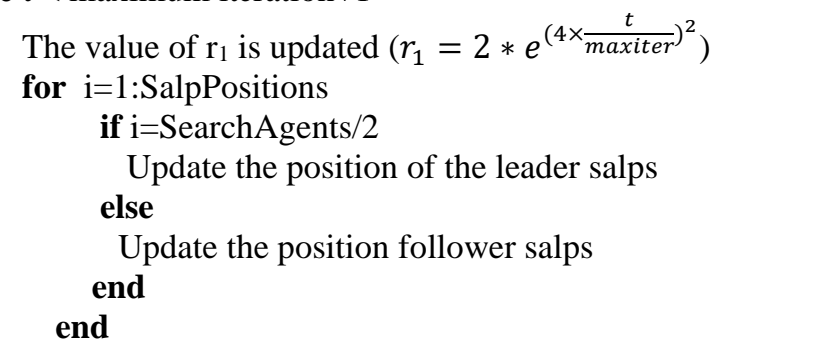

Check the boundaries values of the salp position

end

$\mathrm{t}=\mathrm{t}+1$;

Until the maximum number of iterations is reached

Output best value found so far ; FoodPosition and FoodFitness 


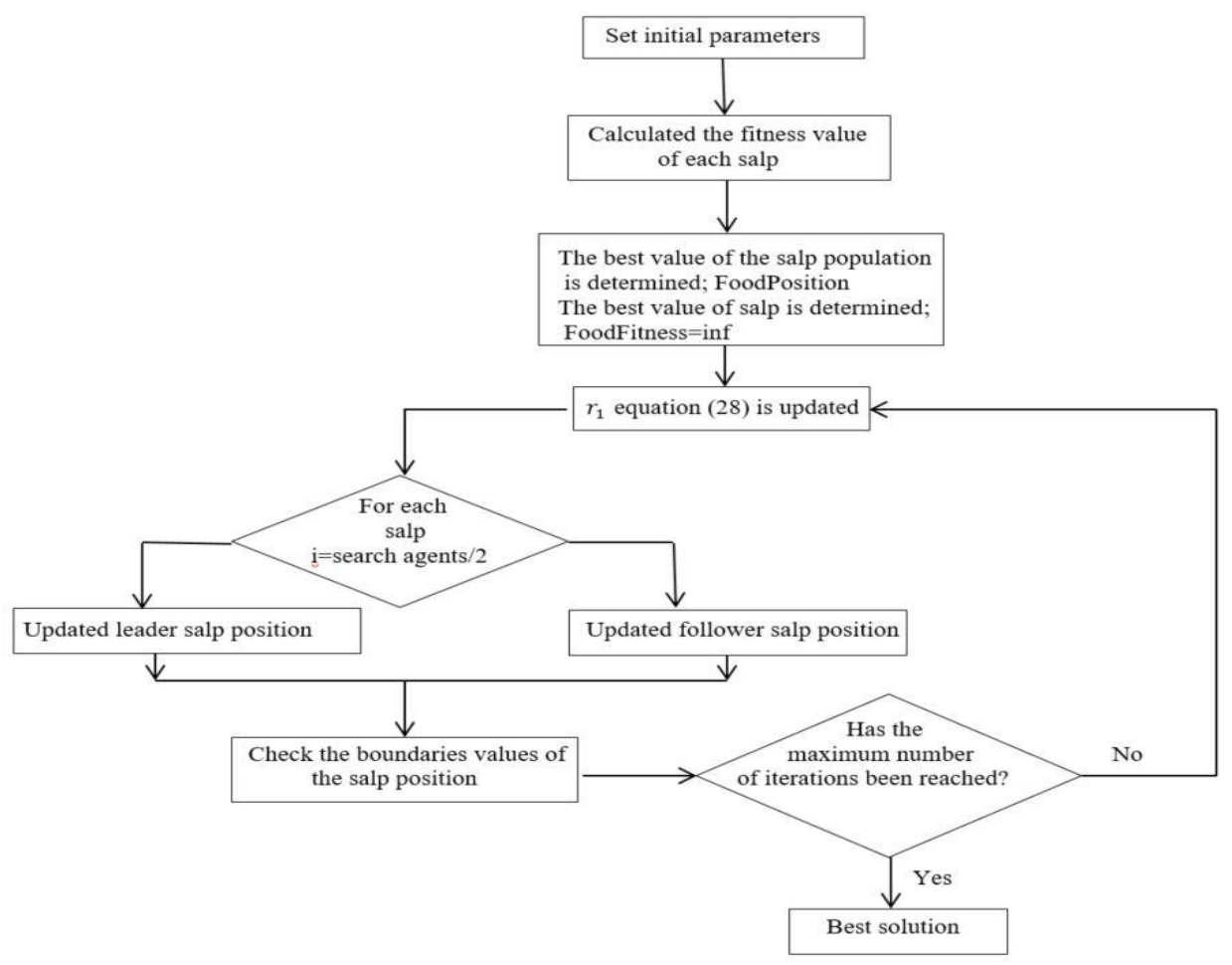

Fig. 4. SSA algorithm flow diagram

$r_{1}=2 \cdot e^{-\left(\frac{4 t}{T}\right)^{2}}$

where $t$ is the number of iterations and $\mathrm{T}$ is the maximum number of iterations. $r_{3}$ indicates whether the position should be at negative or positive infinity. The positions of the follower salps are updated using the following equation.

$y_{j}^{i}=\frac{1}{2}\left(\alpha l^{2}+\beta_{0}{ }^{2}\right)$

$y_{j}^{i}$ i. dimension and j. refers to the positions of the followers. $\beta$ denotes the initial speed and 1 is time.

$\alpha=\frac{\beta_{\text {final }}}{\beta_{0}}$

$\beta=\frac{y-y_{0}}{t}$

Taking $\beta_{0}=0$, the followers at i. its position in dimension is updated by the equation (25) as stated below.

$y_{j}^{i}=\frac{1}{2}\left(y_{j}^{i}+y_{j}^{j-1}\right)$

\subsection{Sine and Cosine Algorithm}

Sine and cosine algorithm is math-based metaheuristic algorithm. SCA has proposed by Mirjalili in 2016 (Mirjalili, et al., 2016). It uses a mathematical model based on sine and cosine functions. In the solution space, candidate solutions are initially launched randomly. Candidate solutions are also constantly updated. The updated individuals fluctuate outward or towards the global optimal solution. After getting the best solution in the algorithm, it is saved and never lost. The sine and function range are updated as the number of iterations increases. In this case, exploitation is guaranteed. Optimization is terminated when the number of iterations obtained in the algorithm exceeds the maximum number of iterations. The optimization process in SCA consist of two stages. These are exploration and exploitation. SCA ensures high reconnaissance and avoidance of local optimum. Also, the result is found in the shortest time.

Pseudo code and flow diagram of SCA are given in Table 4 and in Figure 5 respectively. 
Position is updated using the following equations $(26,27)$ in the SCA algorithm:

$x_{i}^{t+1}=x_{i}^{t}+r_{1} x \sin \left(r_{2}\right) x\left|r_{3} P_{i}^{t}-x_{i}^{t}\right| \quad r_{4}<0.5$

$x_{i}^{t+1}=x_{i}^{t}+r_{1} x \cos \left(r_{2}\right) x\left|r_{3} P_{i}^{t}-x_{i}^{t}\right| \quad r_{4} \geq 0.5$

Where $\mathrm{i}$ is the dimension and $\mathrm{t}$ is the number of iterations. $r_{1}, r_{2}$ and $r_{3}$ are random numbers. $r_{4}$ are random numbers that take values in the range [0 1]. $P_{i}$ indicates the location of the destination in i dimension. $r_{1}$ is used to balance exploration and axploitation and is found by the following equation (28).

$r_{1}=\alpha-t \frac{\alpha}{T}$

where $\mathrm{T}$ is the maximum number of iterations, $\alpha$ is constant value.

Table 4. SCA for Pseudo Code

\section{Initial}

Set search agents

Determine upper and lower limits

Fitness of the best solution found so far gmin=inf

Generate random value

$\mathrm{t}=1$;

while $\mathrm{t}<$ maximum iterations

Check the boundaries

The best values are determined

$$
\begin{aligned}
& \text { if itr_best < gmin } \\
& \text { gmin=itr_best } \\
& \text { gbest=gmin } \\
& \text { end }
\end{aligned}
$$

$r_{1}, r_{2}, r_{3}$ and $r_{4}$ values are updated

The results obtained are updated

end

$t=t+1$

Until the maximum number of iterations is reached

Output best value found so far gbest 


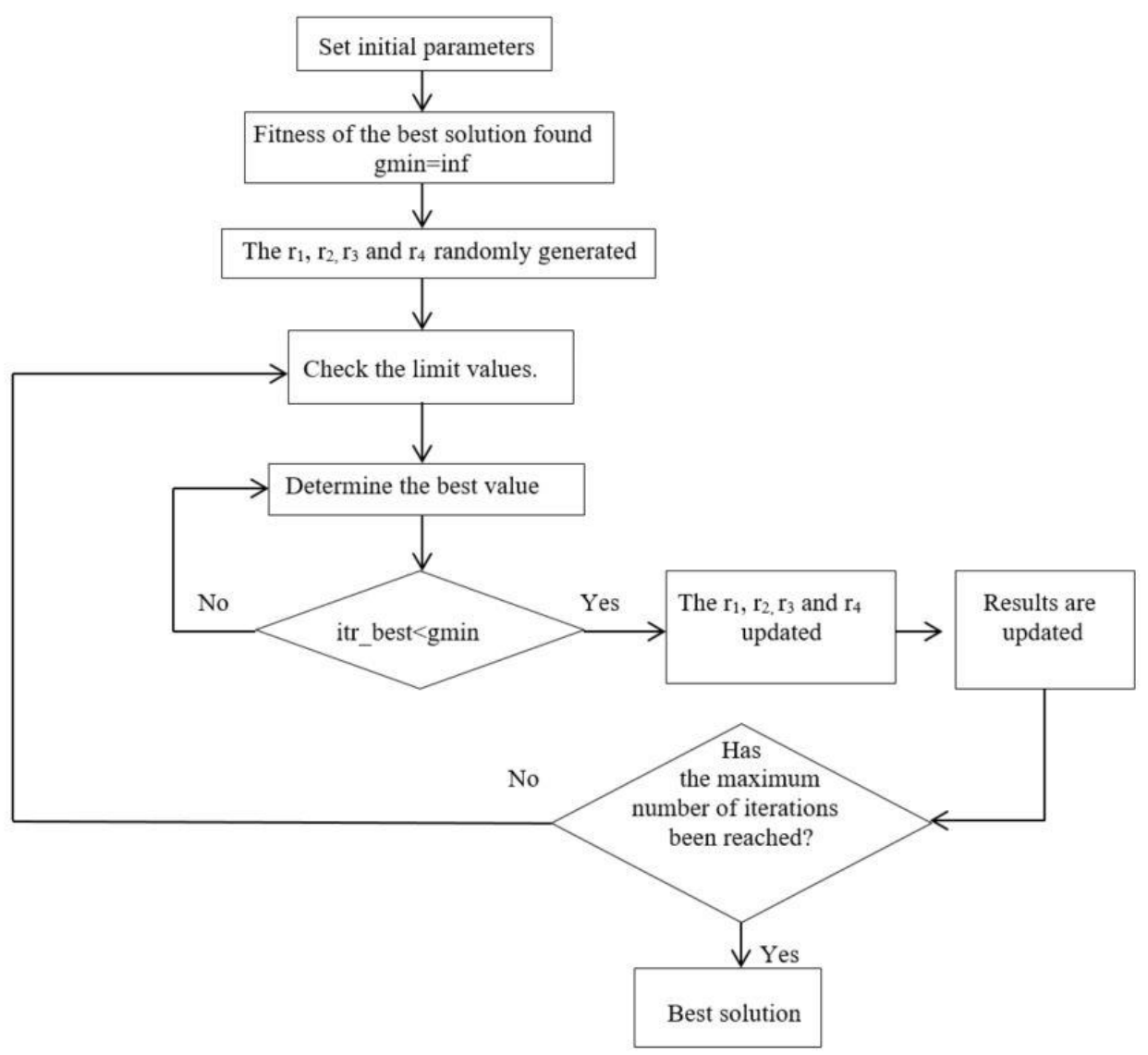

Fig. 5. SCA algorithm flow diagram

\section{Results and Discussion}

This section has been performed by choosing two and four-region power systems. These systems are analyzed for settling time (ST), overshoot (OS) and undershoot (US).

\subsection{Two Region System}

PID-N controller gains obtained with VSA, SSA and SCA on the two-region power system model have simulated in Matlab-Simulink program. System parameters are given in Table 5 (Gozde, et al., 2010):

Table 5. Parameter Value of Two-Region Power System

\begin{tabular}{ll}
\hline Parameters & Value \\
\hline $\mathrm{KP} 1=\mathrm{KP} 2$ & 120 \\
$\mathrm{TP} 1=\mathrm{TP} 2$ & 20 \\
$\mathrm{TG} 1=\mathrm{TG} 2$ & 0.08 \\
$\mathrm{R} 1=\mathrm{R} 2$ & 2.4 \\
$\beta$ & 0.425 \\
$\mathrm{~T}_{12}$ & 0.3 \\
$\mathrm{KR}$ & 0.5 \\
$\mathrm{TR}$ & 10 \\
$\mathrm{~T}_{\mathrm{ij}}$ & 0.3 \\
\hline
\end{tabular}

The control parameters obtained are given Table 6: 
Table 6. Values of Control Parameters Used in Two-Region Power System

\begin{tabular}{lllll}
\hline Method & (Gözde, et al., 2010) & VSA & SSA & SCA \\
\hline $\mathrm{K}_{\mathrm{P} 1}$ & 0.00007 & 16.4262 & 23.9057 & 11.3284 \\
$\mathrm{~K}_{\mathrm{I} 1}$ & 0.1268 & 19.9072 & 24.9998 & 24.9998 \\
$\mathrm{~K}_{\mathrm{D} 1}$ & 0 & 2.9967 & 3.8080 & 2.5202 \\
$\mathrm{~N}_{\text {filt1 }}$ & 0 & 317.0536 & 294.3674 & 563.3867 \\
$\mathrm{~K}_{\mathrm{P} 2}$ & 0.0007 & 18.9853 & 9.6062 & 0.0097 \\
$\mathrm{~K}_{\mathrm{I} 2}$ & 0.1268 & 9.0294 & 3.1111 & 0.0012 \\
$\mathrm{~K}_{\mathrm{D} 2}$ & 0 & 12.9482 & 1.6594 & 2.5510 \\
$\mathrm{~N}_{\text {filt2 }}$ & 0 & 291.9494 & 367.3446 & 409.1876 \\
\hline
\end{tabular}

System performances are given in Figure 6 for region first and second region and Figure 7 for tie line.

(a)

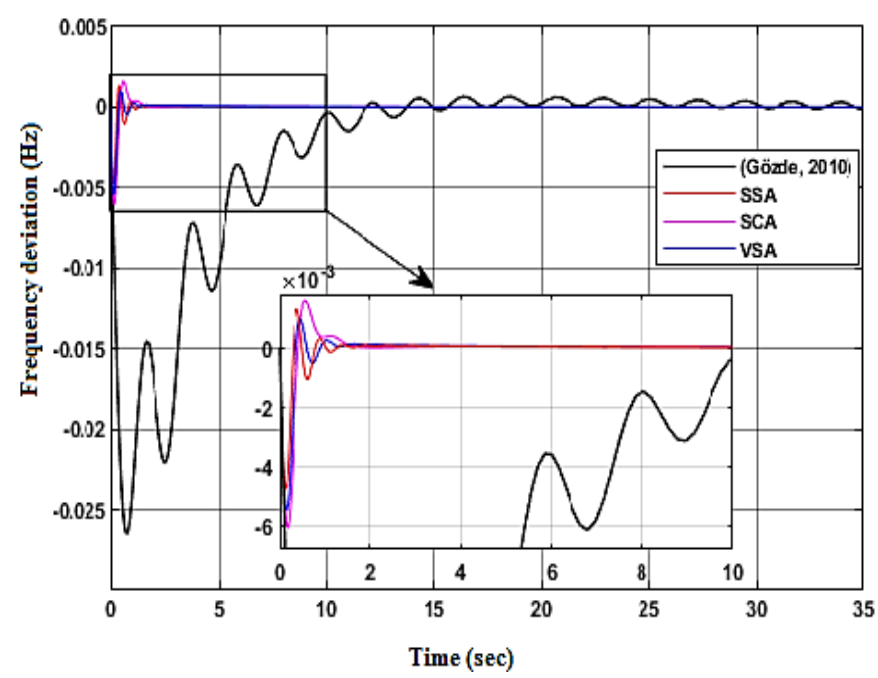

(b)

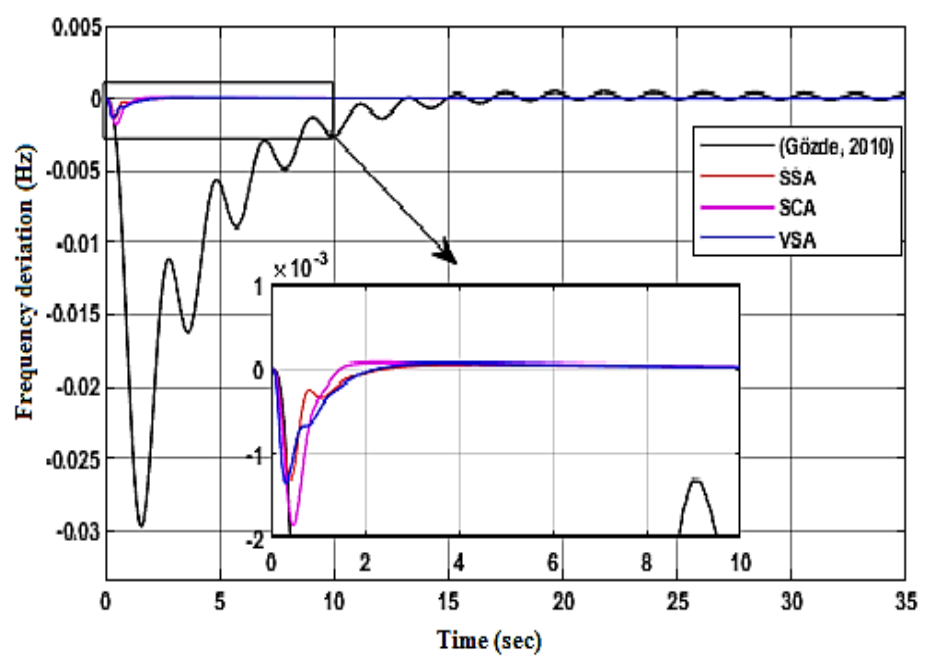

Fig.6. (a) Graph of the first region; (b) Graph of the second region

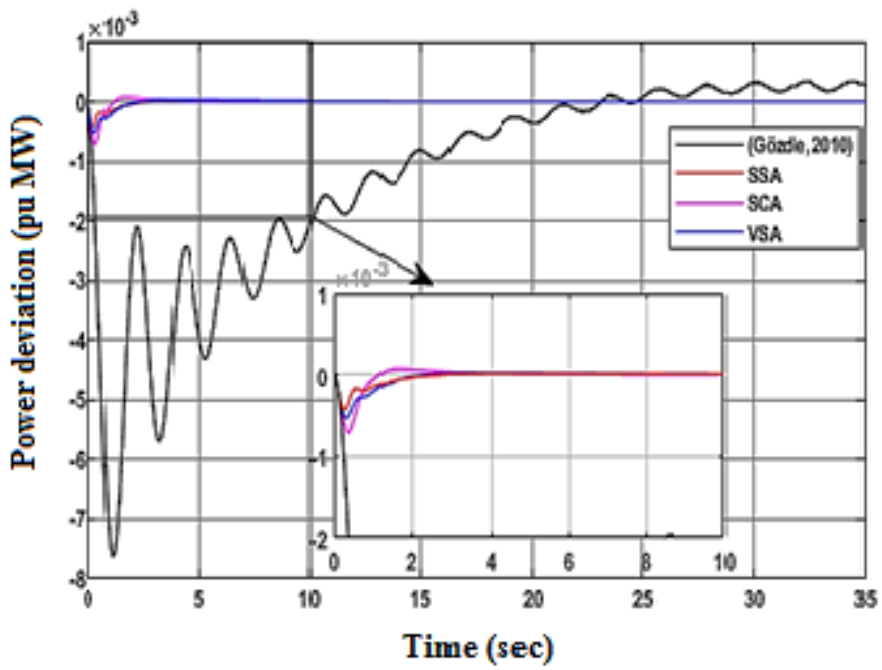

Fig.7. Graph of the tie-line 
Table 7. System Performance Results

\begin{tabular}{llll}
\hline Area 1 & & & \\
\hline Method & ST & OS & US \\
\hline (Gözde,et al., 2010) & 37.199 & 0.0004016 & -0.02591 \\
VSA & 4.630 & 0.0001591 & -0.00264 \\
SSA & $\mathbf{3 . 7 5 0}$ & 0.001306 & -0.004713 \\
SCA & 4.139 & $\mathbf{0 . 0 0 0 0 8 5 4}$ & $\mathbf{- 0 . 0 0 0 1 7 1 3}$ \\
\hline Area 2 & & \\
\hline Method & ST & OS & US \\
\hline (Gözde, et al., 2010) & 40.889 & 0.0001918 & -0.02934 \\
VSA & 5.350 & 0.0000913 & $-\mathbf{0 . 0 0 0 5 9 2 3}$ \\
SSA & $\mathbf{1 . 6 9 5}$ & 0.00004698 & -0.001576 \\
SCA & 1.970 & $\mathbf{0 . 0 0 0 0 4 3 1 3}$ & -0.001082 \\
\hline Tie-Line & & & \\
\hline Method & $\mathbf{S T}$ & $\mathbf{O S}$ & $\mathbf{U S}$ \\
\hline (Gözde, et al., 2010) & 53.552 & 0.0002558 & -0.007548 \\
VSA & 2.230 & 0.0000365 & -0.002322 \\
SSA & $\mathbf{1 . 6 6 3}$ & 0.00002052 & $\mathbf{- 0 . 0 0 0 4 2 9 8}$ \\
SCA & 1.835 & $\mathbf{0 . 0 0 0 0 1 6 4 2}$ & -0.0005066 \\
\hline
\end{tabular}

Comparative system performance results for two region power systems are given in Table 7. In this power system, settling time (ST) band with range is taken as $0.005 \%$. The PID-N value obtained with VSA, SSA, SCA and compared with (Gozde, et al., 2010). Minimum overshoot (OS) values is decreased with SCA and obtained minimum settling time with SSA. Minimum undershoot (US) values have observed in SCA for the first region, VSA for the second region and SSA for the tie line.

\subsection{Four Region System}

PID-N controller gains obtained with VSA, SSA and SCA on the four-region power system model. System parameters are given in Table 8 (Karyeyen, 2009).

Table 8. Parameter Value of Four-Region Power System

\begin{tabular}{ll}
\hline Parameters & Value \\
\hline $\mathrm{KP} 1=\mathrm{KP} 2=\mathrm{KP} 3$ & 120 \\
$\mathrm{~K} 1=\mathrm{KR} 2=\mathrm{KR} 3$ & 0.333 \\
$\mathrm{TP} 1=\mathrm{TP} 2=\mathrm{TP} 3$ & 20 \\
$\mathrm{~T} 1=\mathrm{TG} 2=\mathrm{TG} 3$ & 0.2 \\
$\mathrm{TR} 1=\mathrm{TR} 2=\mathrm{TR} 3$ & 10 \\
$\mathrm{TT} 1=\mathrm{TT} 2=\mathrm{TT} 3$ & 0.3 \\
$\mathrm{R} 1=\mathrm{R} 2=\mathrm{R} 3=\mathrm{R} 4$ & 2.4 \\
$\mathrm{~T}_{1}(4$. Region$)$ & 48.7 \\
$\mathrm{~T}_{2}(4$. Region$)$ & 0.153 \\
$\mathrm{~T}_{3}(4$. Region$)$ & 10 \\
$\mathrm{~T}_{4}(4$. Region) & 1 \\
$\mathrm{~T}_{\mathrm{ij}}$ & 0.0707 \\
$\mathrm{TP} 4$ & 13 \\
$\mathrm{KP} 4$ & 80 \\
\hline
\end{tabular}

The control parameters obtained are given in Table 9: 
Table 9. Values of Control Parameters Used in Four-Region Power System

\begin{tabular}{lllll}
\hline Method & (Karyeyen, 2009) & SCA & SSA & VSA \\
\hline $\mathrm{K}_{\mathrm{P} 1}$ & 0.02 & 24.9998 & 22.7441 & 10.7030 \\
$\mathrm{~K}_{\mathrm{I} 1}$ & 0.06 & 1.3433 & 1.2470 & 0.6977 \\
$\mathrm{~K}_{\mathrm{D} 1}$ & 0 & 11.8886 & 12.0715 & 13.8990 \\
$\mathrm{~N}_{\text {filt1 }}$ & 0 & 675.8056 & 892.3414 & 357.4373 \\
$\mathrm{~K}_{\mathrm{P} 2}$ & 0.02 & 15.6959 & 15.1698 & 2.8929 \\
$\mathrm{~K}_{\mathrm{I} 2}$ & 0.06 & 0.0021 & 3.5469 & 5.1408 \\
$\mathrm{~K}_{\mathrm{D} 2}$ & 0 & 0.0089 & 24.7105 & 22.4857 \\
$\mathrm{~N}_{\text {filt2 }}$ & 0 & $1.0000 \mathrm{e}-03$ & 522.1013 & 85.9580 \\
$\mathrm{~K}_{\mathrm{P} 3}$ & 0.02 & 14.8205 & 6.5847 & 14.7548 \\
$\mathrm{~K}_{\mathrm{I3}}$ & 0.06 & 0.00333 & 16.0118 & 4.3478 \\
$\mathrm{~K}_{\mathrm{D} 3}$ & 0 & 0.1491 & 18.4338 & 3.7061 \\
$\mathrm{~N}_{\text {filt3 }}$ & 0 & 400.9137 & 413.8440 & 900.2058 \\
$\mathrm{~K}_{\mathrm{P} 4}$ & 0.02 & 0.2879 & 0.7230 & 2.9002 \\
$\mathrm{~K}_{\mathrm{I} 4}$ & 0.06 & 10.8305 & 5.2919 & 6.2792 \\
$\mathrm{~K}_{\mathrm{D} 4}$ & 0 & 20.4070 & 3.3301 & 7.6561 \\
$\mathrm{~N}_{\text {filt4 }}$ & 0 & 999.9900 & 942.6775 & 22.6250 \\
\hline
\end{tabular}

System performances are given in Figure 8 for region 1, region 2, region 3 and region 4, in Figure 9 for tie line of region 1, tie line of region 2, tie line of region 3 and tie line of region 4.

(a)

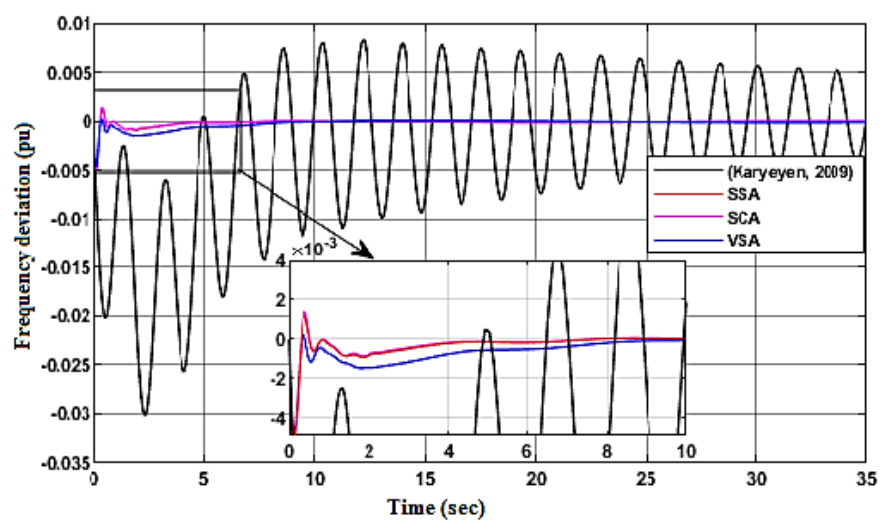

(c)

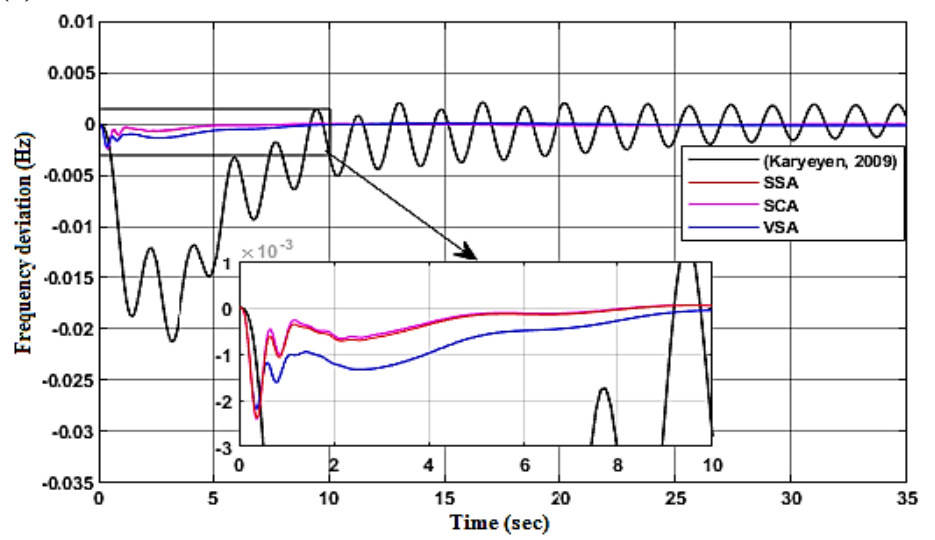

(b)

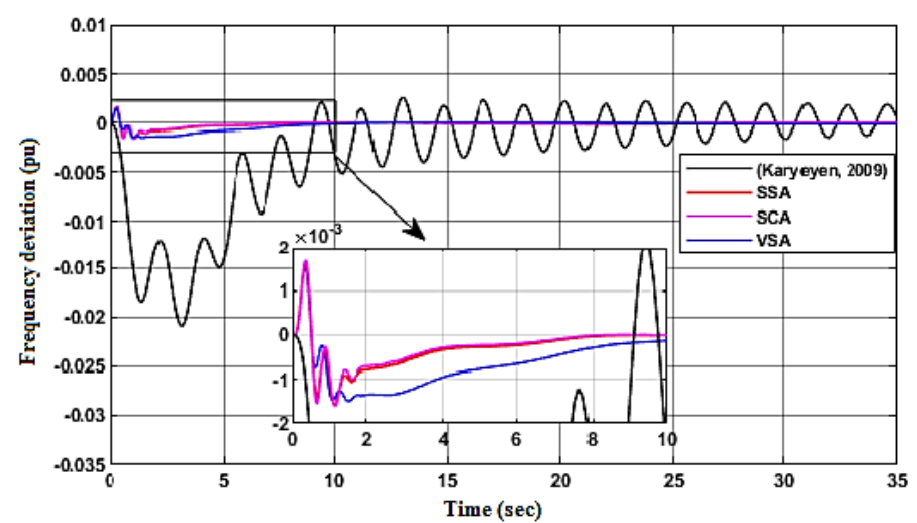

(d)

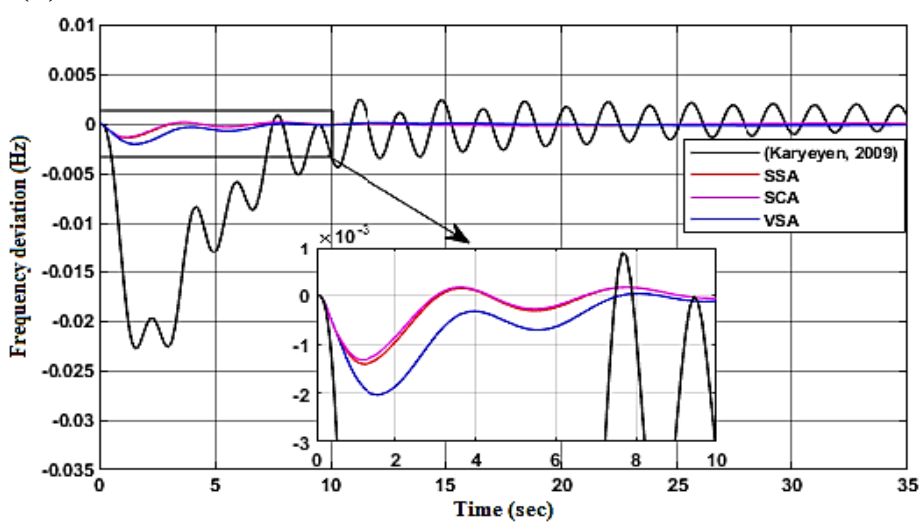

Fig.8. (a) Graph of the first region; (b) Graph of the second region; (c) Graph of the third region; (d) Graph of the fourth region 
(a)

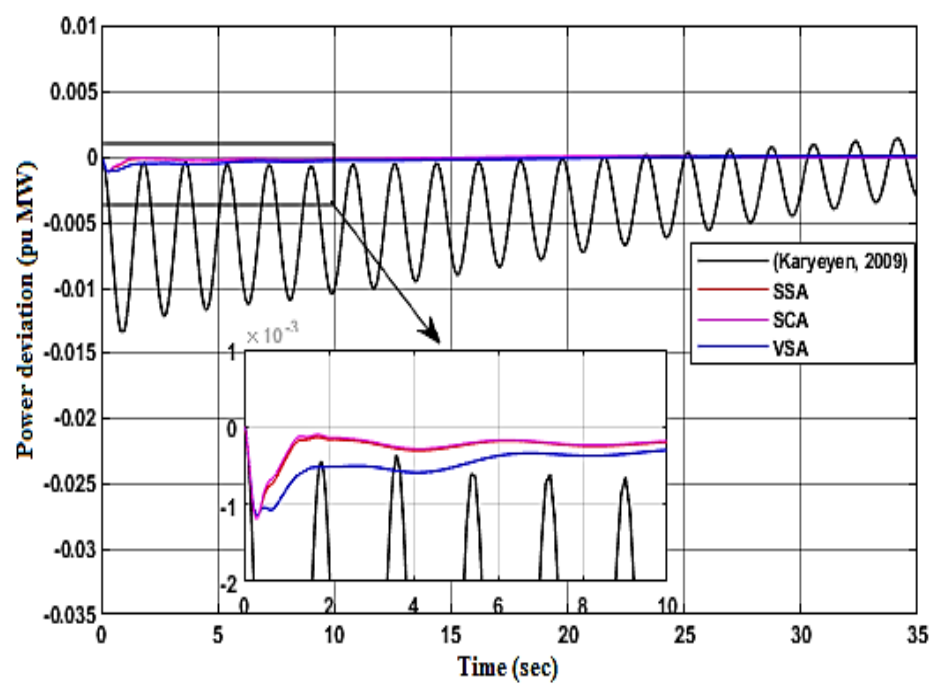

(c)

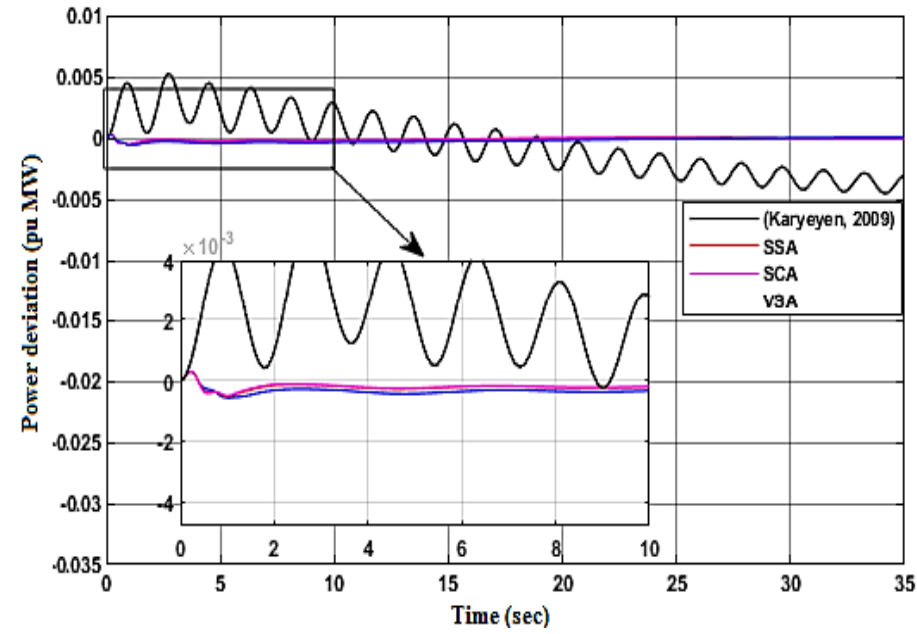

(b)

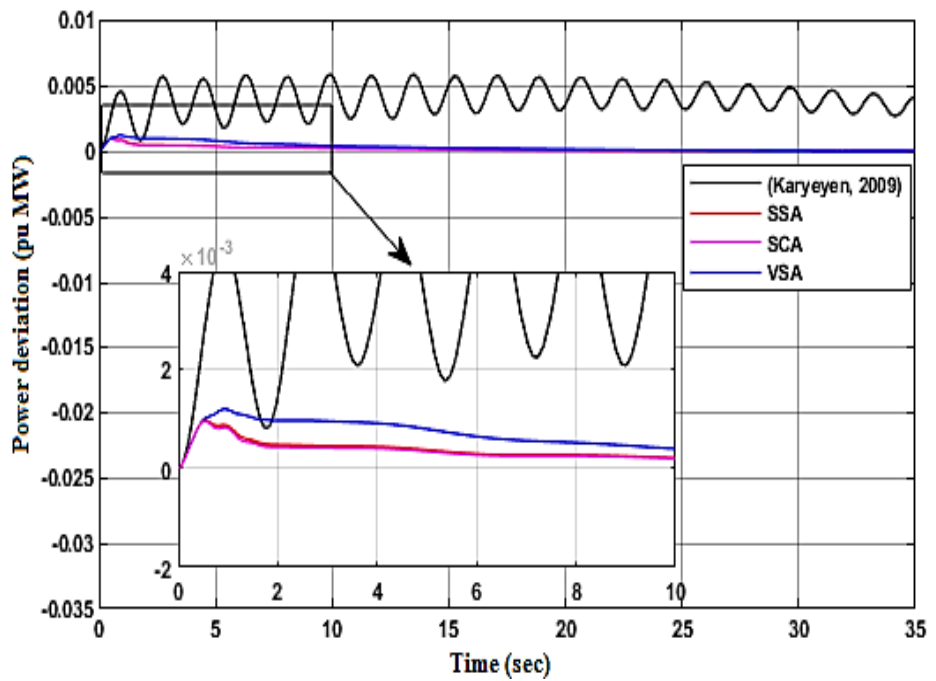

(d)

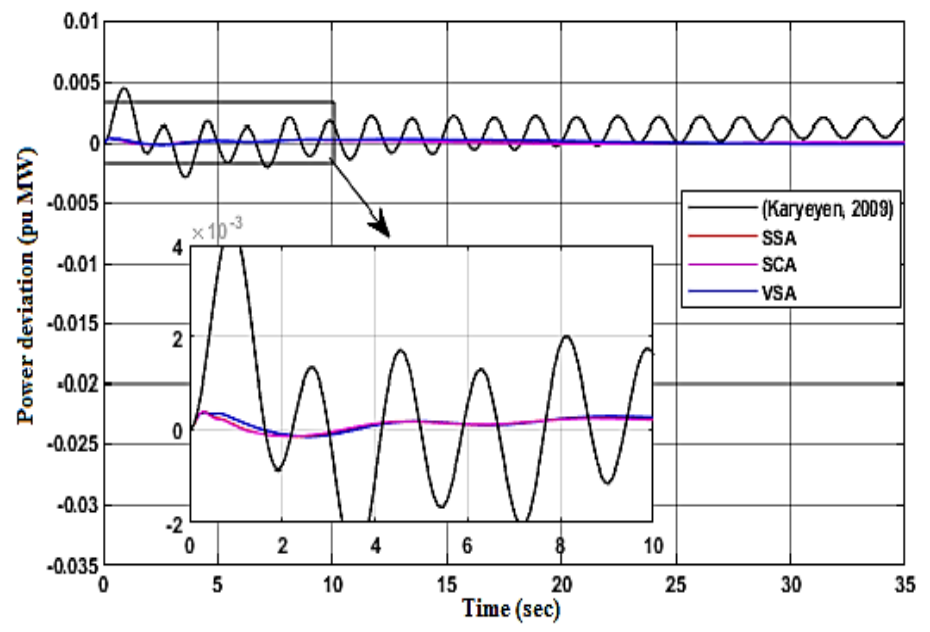

Fig.9. (a) Graph of the tie-line 1; (b) Graph of the tie-line 2; (c) Graph of the tie-line 3; (d) Graph of the tie-line 4 Comparative system performance results of frequency deviation for each region are given in Table 10:

Table 10. System Performance Results of Frequency Deviation

\begin{tabular}{llll}
\hline Area1 & & & \\
\hline Method & ST & OS & US \\
\hline (Karyeyen, 2009) & 140.592 & 0.008348 & -0.03016 \\
VSA & 6.360 & $\mathbf{0 . 0 0 0 2 3 5 1}$ & $\mathbf{- 0 . 0 0 4 7 0 2}$ \\
SSA & 3.024 & 0.001170 & -0.004895 \\
SCA & $\mathbf{2 . 8 4 0}$ & 0.001394 & -0.004926 \\
\hline Area2 & & & \\
\hline Method & ST & $\mathbf{O S}$ & US \\
\hline Karyeyen, 2009) & 136.150 & 0.002600 & -0.02090 \\
VSA & 6.868 & $\mathbf{0 . 0 0 1 5 3 2}$ & $\mathbf{- 0 . 0 0 1 4 9 2}$ \\
SSA & 3.300 & 0.001661 & -0.001586 \\
SCA & $\mathbf{3 . 0 7 0}$ & 0.001692 & -0.001612 \\
\hline
\end{tabular}


Table 10 (Continued). System Performance Results of Frequency Deviation

\begin{tabular}{llll}
\hline Area3 & & & \\
\hline Method & ST & OS & US \\
\hline Karyeyen, 2009) & 139.700 & 0.002123 & -0.02128 \\
VSA & 6.003 & 0.00008331 & $-\mathbf{0 . 0 0 2 1 9 0}$ \\
SSA & 3.511 & $\mathbf{0 . 0 0 0 0 4 6 0 4}$ & -0.002379 \\
SCA & $\mathbf{3 . 3 1 5}$ & 0.00005147 & -0.002460 \\
\hline Area4 & & & \\
\hline Method & ST & OS & US \\
\hline Karyeyen, 2009) & 129.000 & 0.002466 & -0.02279 \\
VSA & 6.400 & 0.0001121 & $\mathbf{- 0 . 0 0 2 0 4 1}$ \\
SSA & 2.481 & $\mathbf{0 . 0 0 0 1 6 1 9}$ & -0.001411 \\
SCA & $\mathbf{2 . 3 9 0}$ & 0.000161 & -0.001329 \\
\hline
\end{tabular}

Comparative tie line power deviation for each region are given in Table 11.

Table 11. System Performance Results of Frequency Deviation

\begin{tabular}{llll}
\hline Tie Line 1 & & & \\
\hline Method & ST & OS & US \\
\hline Karyeyen, 2009) & 304.642 & 0.003153 & -0.01347 \\
VSA & 5.089 & 0.00007001 & $\mathbf{- 0 . 0 0 1 1 3 9}$ \\
SSA & 0.909 & 0.00003981 & -0.001189 \\
SCA & $\mathbf{0 . 8 5 5}$ & $\mathbf{0 . 0 0 0 0 3 7 3 6}$ & -0.001189 \\
\hline Tie Line 2 & & & \\
\hline Method & ST & OS & US \\
\hline Karyeyen, 2009) & 315.779 & 0.005824 & -0.002057 \\
VSA & 8.257 & $\mathbf{0 . 0 0 1 1 8 8}$ & -0.000006034 \\
SSA & 1.670 & 0.0009585 & $\mathbf{0 . 0 0 0 e + 0 0 0 0}$ \\
SCA & $\mathbf{1 . 5 1 6}$ & 0.000941 & $\mathbf{0 . 0 0 0 e + 0 0}$ \\
\hline Tie Line 3 & & & \\
\hline Method & $\mathbf{S T}$ & $\mathbf{O S}$ & US \\
\hline Karyeyen, 2009) & 329.633 & 0.005231 & -0.004688 \\
VSA & 1.480 & $\mathbf{0 . 0 0 0 2 6 4 5}$ & -0.0005791 \\
SSA & 1.100 & 0.0002808 & -0.0005304 \\
SCA & $\mathbf{1 . 0 7 0}$ & 0.0002829 & $\mathbf{- 0 . 0 0 0 5 1 4 9}$ \\
\hline Tie Line 4 & & & \\
\hline Method & ST & $\mathbf{O S}$ & US \\
\hline (Karyeyen, 2009) & 146.619 & 0.004449 & -0.002919 \\
VSA & 0 & $\mathbf{0 . 0 0 0 3 7 6 6}$ & -0.0001541 \\
SSA & 0 & 0.0003938 & -0.0001528 \\
SCA & 0 & 0.000394 & $\mathbf{- 0 . 0 0 0 1 4 7}$ \\
\hline
\end{tabular}

In this power system, settling time (ST) band with range is taken as $0.05 \%$. Minimum settling time is obtained with for SCA for all regions. In addition, mostly minimum OS and US values are obtained with VSA for regions. For considered tie line performances, SCA mostly give better outputs than VSA and SSA (Karyeyen, 2009). 


\section{Conclusions}

In this study, load frequency control of two different interconnected power systems consisting of two and four region has been performed. The results obtained using the same model of (Gözde, et al., 2010) two region and (Karyeyen, 2009) for four region are compared. The population size is taken as 50 in the algorithms. Optimal parameter values of the proposed PID-N controller have been found by VSA, SSA and SCA methods. The results found are presented comparatively graphically and numerically. System performance results are compared in Table 7 for two region interconnected power system and in Table 10 for the four region interconnected power system. SSA gives lower settling time for two region and SCA gives lower settling time for four region. However, different techniques gives better results for different regions for overshoot and undershoot values. When analysis all numerical results, it can be said that SCA shows generally better performance compared with the other techniques.

\section{References}

Ali, E.S., \& Abd-Elazim, S.M. (2011). Bacteria foraging optimization algorithm based load frequency controller for interconnected power system, International Journal of Electrical Power \& Energy System, 33(3), 633-638.

Çam, E., \& Kocaarslan, İ. (2002). Tek Bölgeli Güç Sistemlerinde Bulanık Mantık İle Yük Frekans Kontrol, Teknoloji, 5(3-4), 73-77.

Dogan, B., \& Olmez, T. (2015). A new metaheuristic for numerical function optimization: Vortex Search Algorithm, Information Sciences, 293, 125-145.

Formato, F.A. (2007). Central Force Optimization: A New Metaheuristic With Applications in Applied Electromagnetics, 77, 425491.

Gözde, V., Taplamacıŏlu, M.C., Kocaarslan, İ., \& Şenol, M.A. (2010). İki Bölgeli Ara-Isıtmalı Termal Güç Sisteminin Yük-Frekans Kontrolü İçin Parçacık Sürüsü Optimizasyon Tabanlı PI-Kontrolör, Isı Bilim ve Tekniği Dergisi, 30(1), 13-21.

Gümüş, K.K. (2012). Güç Santrallerinde Primer Frekans Ve Yük Kontrolü, Yüksek Lisans Tezi, İstanbul Üniversitesi.

He, S., Wu, Q.H., \& Saunders, J.R. (2009). Group Search Optimizer: An Optimization Algorithm Inspired by Animal Searching Behaviour, IEEE Transaction on Evolutionary Computation, 13(5), 973-990.

Hooke, R., \& Jeeves, T.A. (1961). Direct search solution of numerical and statistical problems, J. Assac. Comput. Mach. (ACM), 8(2), 212-229.

Karyeyen, A. (2009). Çok Bölgeli Elektrik Güç Sistemlerinde Optimum Yük-Frekans Kontrolü, Yüksek Lisans Tezi, Selçuk Üniversitesi, Konya, 106.

Karyeyen, A., Çetinkaya, N., \& Güntay, S. (2009). İki Bölgeli Elektrik Güç Sistemlerinde Optimum Yük-Frekans Kontrolü, Elektrik, Elektronik, Bilgisayar ve Biyomedikal Mühendisliği 13. Ulusal Kongresi.

Kashan, A.H. (2009). League Championship Algorithm: A new algorithm for numerical function optimization.’International Conference of Soft Computing and Pattern Recognition, 43-48.

Kocaarslan, İ., Gümüş, K.K., Bal, E., \& Tiryaki, H. (2012). Modern Optimizsyon Yöntemleri (ABC, PSO) ile Yük-Frekans Kontrolü, ELECO 2012 Elektrik - Elektronik ve Bilgisayar Mühendisliği Sempozyumu. Bursa, 94-98.

Mirjalili, S. (2016). SCA: A Sine Cosine Algorithm for solving optimization problems, Knowl.-Based Syst, 96, $120-133$.

Mirjalili, S., Gandomi, A.H., Mirjalili, S.Z., Saremi, S., Faris, H., \& Mirjalili, S.M. (2017). Salp Swarm Algorithm: A bio-inspired optimizer for engineering design problems, Advances in Engineering Software, 114, 163-191.

Naidu, K., Mokhlis, H., \& Bakar, A.H.A. (2013). Application of Firefly Algorithm (FA) based optimization in load frequency control for interconnected reheat thermal power system, IEEE Jordan Conference on Applied Electrical Engineering and Computing Technologies (AEECT).

Omar, M., Ebrahim, M.A., Abdel Ghany, A.M., \& Bendary, F. (2015). Harmony Search based PID for Multi Area Load Frequency Control Including Boiler Dynamics and Nonlinearities, Wseas Transactions on Circuits and Systems, 14, 407-414. 
Omar, M., Soliman, M., Ghany, A.M.A., \& Bendary, F. (2013). Ant Colony Optimization based PID for single Area Load Frequency Control, International Conference on Modelling, Identification \& Control, 119-123.

Ozkop, E., Altas, I.H., \& Sharaf, A.M. (2010). Load Frequency Control in Four Region Power Systems Using Fuzzy Logic PI Controller, 16th National Power Systems Conference, 232-236.

Özdemir, M.T., \& Öztürk, D. (2016). İki Bölgeli Güç Sisteminin Optikten Esinlenen Optimizasyon Algoritması ile Optimal Yük Frekans Kontrolü, Firat Üniv. Müh. Bil. Dergisi, 28(2), 57-66.

Rathor, S., Acharya, D.S, Gude, S., \& Mishra, P. (2011). Application Artificial Bee Colony Optimization for Load Frequency Control, Conference Paper.

Safi, S.J., Tezcan, S.S., Eke, İ., \& Farhad, Z. (2018). Gravitatinal Search Algorithm (GSA) Based PID Controller Design for Two Region Multi-Source Power System Load Frequency Control (LFC), Gazi University Journal of Science, 31(1), 139-153.

Sahu, B.K., Pati, S., Mohanty, P.K., \& Panda, S. (2015). Teaching-learning based optimization algorithm based fuzzy-PID controller for automatic generation control of multi-are power system, Applied Soft Computing, 27, 240-249.

Sahu, R.K., Panda, S., \& Pandhan, S. (2014). Optimal gravitational search algoritm for automatic generation control of interconnected power systems, Ain Shams Engineering Journal. http://dx.doi.org/10.1016/j.asej.2014.02.004.

Sayed, G.I., Khoriba, G., \& Haggag, M.H. (2018). A novel chaotic salp swarm algorithm for global optimization and feature selection, Applied Intelligence, https://doi.org/10.1007/s10489-018-1158-6.

UCTE (2004). UCTE Operation Handbook-A1:Load-Frequency Control and Performance.

Yamaçlı, V., Abacı, K., \& Özer, Z. (2014). Üç Bölgeli bir Güç Sisteminde Yük-Frekans Kontrolü İçin Yapay Sinir Ağları Tabanlı Bir Kontrolör Tasarımı, Eleco 2014 Elektrik-Elektronik-Bilgisayar ve Biyomedikal Mühendisliği Sempozyumu. Bursa, 124-128.

Yanmaz, K., Altaş, İ.H., \& Mengi, O.Ö. (2008). Çok Bölgeli Güç Sistemlerinde Yük Frekans Kontrolünün Bulanık Mantık Denetleyici ile Gerçekleştirilmesi, Akıllı Sistemlerde Yenilikler ve Uygulamaları Sempozyumu. Isparta, 259-262.

Yalçın, E., Çam, E., \& Lüy, M. (2010). Dört Bölgeli Güç Sisteminde PID Kontrolör ile Yük-Frekans Kontrolü, National Conference on Electrical, Electronics and Computer Engineering, 72-77.

Yalçın, E., Çam, E., Vardar, T. and Lüy, M. (2013). PID Kontrolör ile İki Bölgeli Güç Sistemlerinde Yük Frekans Kontrolünün İncelenmesi, International Journal of Engineering Research and Development, 5(2). 